\title{
LA TEORÍA DE LA JUSTICIA EN ANTONIO GÓMEZ ROBLEDO
}

MAURICIO BEUCHOT

INSTITUTO DE INVESTIGACIONES FLLLÓGICAS

UNIVERSIDAD NACIONAL AUTÓNOMA DE MÉXICO

\section{Introducción}

Este artículo quiere ser un homenaje al doctor Antonio Gómez Robledo, quien acaba de morir el 3 de octubre de 1994. Fue miembro ilustre del Instituto de Investigaciones Filosóficas de la UNAM y uno de los pensadores más sólidos y completos de México en este siglo. Primero presentaré una sucinta biografía de Gómez Robledo y un elenco de sus principales obras filosóficas. Dejo de lado su rica actividad jurídica y diplomática, por no pertenecer a lós límites de este ensayo. Después detallaré la exposición de la justicia en el pensamiento de Gómez Robledo, que es fundamentalmente la de Santo Tomás de Aquino, pero con notables esclarecimientos, aplicaciones y adaptaciones en función de la iusfilosofía actual. En efecto, Gómez Robledo conocía de manera eminente la historia de la filosofía del derecho en todas sus épocas y de todas se beneficiaba para su sistematización. Como es natural, tengo, respecto de Gómez Robledo, algunas discrepancias interpretativas del texto y la doctrina del Aquinate; pero, si me permito alguna objeción o matización, sólo es para honrar su tomismo vivo y actuante, el cual se nutre del diálogo entre los propios tomistas y con los otros pensadores de su momento histórico.

\section{Vida y obra filosofica de Gómez Robledo}

Antonio Gómez Robledo era oriundo de Guadalajara, Jalisco, donde nació en 1908. Estudió humanidades en el colegio jesuita y derecho en la universidad de Guadalajara. De sus maestros jesuitas, como él mismo dice, aprendió "el sentido de la filosofía perenne". 1 De sus maestros de jurisprudencia de ese tiempo aprendió el respeto y el aprecio por el derecho natural. ${ }^{2}$ Pasó

1 A. Gómez Robledo, "Vita et opera", en Oratio doctoralis. Últimos escritos, El Colegio de Jalisco, Guadalajara, 1994, p. 23.

2 Es lo que dice en la "Entrevista con el doctor Antonio Gómez Robledo", en Antonio Gómez Robledo. Imagen y obra escogida, UNAM/CESU, México, 1984 (Colección México y la 
a estudiar filosofía en la ciudad de México, en cuya Universidad Nacional Autónoma obtuvo la maestría y el doctorado. En esta capital se dedicó igualmente al derecho internacional, en la Secretaría de Relaciones Exteriores, así como al servicio diplomático.

Desde pronto se entregó a la labor filosófica, pues se inició como profesor de introducción a la filosofía en la Escuela Nacional Preparatoria (19391943). En la Facultad de Filosofía y Letras de la UNAM impartió las cátedras de filosofía griega, filosofía de los valores y filosofía de la religión. Fue jefe del Departamento de Humanidades y profesor de filosofía en el Instituto Tecnológico y de Estudios Superiores de Monterrey (1947-1948). Dos veces fue director interino del Centro de Estudios Filosóficos de la UNAM (1946 y 1954), después Instituto de Investigaciones Filosóficas. En este último fue investigador desde 1984 hasta su muerte, acaecida diez años después. Ingresó a la Academia Mexicana de la Lengua en 1956 y al Colegio Nacional en 1961. Fue miembro y además dictaminador del Sistema Nacional de Investigadores.

Entre sus libros, los más relacionados con la temática filosófica son los siguientes: Política de Vitoria (UNAM, 1940); Cristianismo y filosofía en la experiencia agustiniana (UNAM, 1942), que fue su tesis para el grado de maestro de filosofía; La filosofía en el Brasil (UNAM, 1946), que fue su tesis para el doctorado; Ensayo sobre las virtudes intelectuales (UNAM/FCE, 1957); Meditación sobre la justicia (UNAM/FCE, 1963); Sócrates y el socratismo (UNAM/FCE, 1966); Platón, los seis grandes temas de su filosofía: la virtud, las ideas, el alma, el amor, la educación y el estado (UNAM/FCE, 1974); El pensamiento filosófico de Edith Stein (UNAM, 1988), y Estudios pascalianos (FCE, 1992).

Del griego tradujo: Aristóteles, Ética nicomaquea (UNAM, 1954), Política (UNAM, 1963) y Ética eudemia (UNAM, 1994); Platón, La república (UNAM, 1971); Marco Aurelio, Pensamientos (UNAM, 1993). Del latín, dos dubia del De dominio infidelium et iusto bello de Fray Alonso de la Veracruz, así como algunos otros textos, en A. Gómez Robledo, El magisterio filosófico y jurídico de Alonso de la Veracruz, Porrúa, México, 1984.

Mencionaré además algunos de sus artículos sobre estos temas filosóficos: "Vitoria y nosotros", Letras de México, no. 32, 1938; "La doctrina aristotélica del justo medio", Revista de Estudios Universitarios, vol. I, no. 2, 1939; "El pensamiento de Calicles", Revista de la Escuela Nacional de Jurisprudencia, vol. II, nos. 7-8, 1940; "Teodicea de Aristóteles", Ábside, vol. IV, no. 2, 1940; "Reflexiones sobre Bergson", Ábside, vol. V, nos. 4-5, 1941; "Recordación de Vitoria", Cuadernos Americanos, vol. V, no. 6, 1946; "Vitoria, comentador de Santo Tomás", Filosofía y Letras, vol. XII, no. 23, 1946; 
"Homenaje al maestro Antonio Caso", prólogo al libro publicado por el Centro de Estudios Filosóficos, Ed. Stylo, México, 1947; "Vida y pensamiento de Descartes", Onda (Monterrey), 1947; "La teoría de las pasiones en Descartes y en la tradición filosófica", Filosofía y Letras, vol. XIV, no. 28, 1947; "Introducción a la ética aristotélica", Filosofía y Letras, nos. 43-44, 1951; "La ética de los valores", Ábside, vol. XVII, no. 3, 1953; "La ética de San Agustín", Diánoia; "Filosofía y lenguaje", discurso de recepción en la Academia Mexicana de la Lengua, con respuesta de Agustín Yáñez, México, 1956; "Ser y valor", comunicación al II Congreso Nacional de Filosofía, Sao Paulo, noviembre, 1959; "Diplomacia y filosofía", conferencia pronunciada en ese mismo congreso; "La justicia en Platón", Memoria de El Colegio Nacional, 1961; "Mis recuerdos de Gaos", Cuadernos Americanos, vol. XXVIII, no. 5, 1969; "Nicolás Maquiavelo en su quinto centenario", en la edición de El Príncipe, Ed. Porrúa, 1970; "Estudio preliminar" a F. de Vitoria, Relecciones, Ed. Porrúa, 1974; "Le droit naturel de nos jours", comunicación al Congreso Mundial de Filosofía del Derecho, Basilea, 1978; "La estética de Tomás de Aquino en el pensamiento de Umberto Eco", folleto, UNAM, 1988; "La democracia ateniense", Diánoia (UNAM), no. 36, 1990, y "Sobre la concepción estoica del derecho natural", Ethos (Buenos Aires), nos. 920, 1991-1992. La producción filosófica de Gómez Robledo fue abundante y de muy alta calidad.

\section{La teoría de la justicia}

En su libro Meditación sobre la justicia, Antonio Gómez Robledo estudia esta idea a lo largo de la historia. Después de Platón, Aristóteles y los estoicos, trata a Santo Tomás de Aquino. Luego sigue con Leibniz, Kant y otros modernos. Pero el Aquinate es a quien él sigue personalmente. Señala que Tomás no es un mero comentador ni repetidor del Estagirita, porque casi siempre explicita las virtualidades del texto comentado. Aporta algo. Gómez Robledo se centra sobre todo en la Summa theologix, donde se encuentra el pensamiento más maduro de Santo Tomás. Allí se nos dice que la justicia es una virtud y la virtud se especifica por su objeto; el objeto de esta virtud es el derecho. Gómez Robledo apunta que la distinción entre derecho y justicia es un avance respecto de Aristóteles y todos los griegos, y la razón de este avance es la mediación del genio jurídico de los romanos. La justicia es una facultad moral y el derecho un conjunto de normas para actuar. Ahora, en cambio, ya no se concibe la justicia como una virtud, sino como el ideal al que tiende el derecho.

Ahora bien, el derecho por antonomasia es para Tomás - como lo señala bien Gómez Robledo- el derecho natural. Este no es considerado en la actualidad como derecho. "Para llegar a serlo, ha de pasar por la instancia mediadora, $y$ desde luego decisiva, de la conciencia o sentimiento del valor 
(Wertempfinden, Werteinfühlung) en el legislador o en la comunidad, a fin de adquirir, por esta ineludible mediación, la plena consistencia jurídica."3 En cambio, la escolástica sostenía el derecho natural sin necesidad de esa instancia, como algo subsistente por sí mismo. Más bien el derecho natural es el que sirve de norma y criterio para el derecho positivo, de modo que si llega a haber alguna ley positiva contraria a la ley natural, se invalida.

Gómez Robledo hace ver que Santo Tomás es el primero en distinguir entre derecho y ley, "al decir que la ley no es el derecho mismo, si hablamos con propiedad, sino más bien la regla o el fundamento del derecho (II-II, q. 57 , a. 1 , ad $2 \mathrm{~m}$.)". 4 Comenta además una cosa de gran importancia: "En este aspecto, la filosofía aristotélico-tomista concuerda con las teorías modernas del derecho, para las cuales el fenómeno jurídico no se agota en la norma general, sino que se extiende a los actos más concretos, más determinativos del derecho individual, como son el contrato privado, la sentencia judicial y el acto administrativo." Algo también muy relevante es lo que agrega Gómez Robledo: las objeciones de Kelsen contra el derecho natural no tocan a Tomás, ya que no procede por deducciones lógicas para fundar el derecho.

Varias cosas aporta el Aquinate más allá de Aristóteles, porque medió no sólo el derecho romano, sino además la revelación cristiana. Esta última hizo que Santo Tomás ideara muchas cosas en filosofía que no se encontraban en los griegos. Una de esas cosas es el que la justicia y el derecho no están completamente embebidos en la sociedad política. La ley natural es superior al estado y, así, lo justo natural no es ya una de las especies de lo justo político. Y es que la revelación le hacía ver que el individuo, aunque está ordenado a la sociedad civil, no lo está en todos los respectos. Por ejemplo, y nada menos, no lo está en cuanto a su destino ultraterreno y sobrenatural. Gómez Robledo señala bien estos puntos en los que el filósofo medieval trasciende al filósofo antiguo. El lugar que Tomás da a la ley natural es mayor que el que le daba Aristóteles.

Otro punto capital es el manejo que hace Tomás del derecho de gentes. Aristóteles nunca lo tomó como objeto expreso de sus reflexiones. Este derecho provenía más bien de la tradición romanista. San Isidoro divide el derecho en natural, civil y de gentes. Santo Tomás había hablado de derecho natural y positivo. ¿Cómo se podía integrar el de gentes? Para los romanos ese derecho normaba sus relaciones con los extranjeros o entre los extranjeros que caían bajo la jurisdicción romana; por ejemplo, regulaba el comercio. De esta manera, no se dejaba al no romano fuera de la ley. Se podría decir que constituía la parte del derecho romano que se mostraba con

3 A. Gómez Robledo, Meditación sobre la justicia, FCE, México, 1963, p. 99.

4 Ibid., p. 103.

5 Ibid. 
cierta validez universal. Ulpiano (ca. 228 a.C.) ve el derecho natural como el común a todos los animales, al de gentes como el que se observa entre todos los pueblos, y al civil como el que rige para cada pueblo. Gayo ( $c a$. 160 a.C.) sólo pone derecho de gentes y derecho civil y defiende el primero como el que la razón natural ha establecido para todos los hombres. Hacía al derecho natural algo aplicable sólo a los hombres. Así, mientras que Ulpiano parecía hacer al derecho de gentes algo cercano al civil, Gayo lo hacía algo cercano al natural. Santo Tomás dice que el derecho de gentes no se reduce al natural, sino que es algo derivado de él. En efecto, lo justo natural puede ser de dos modos: (a) de modo absoluto, como que el hombre y la mujer engendren, y (b) de modo relativo a ciertas consecuencias, como la propiedad privada. Esta última no tiene que ser algo absoluto, pero si queremos que haya paz entre los individuos, tenemos que admitir que una cosa sea de uno y otra de otro. De este modo, Santo Tomás mantiene las divisiones influyentes de Ulpiano y de Gayo, diciendo que hay derecho natural, de gentes y positivo; éstas hacen que el de gentes se aproxime al derecho natural, pero que se diferencie de él en que requiere de la operación racional; así no es aplicable a todos los animales (y se distingue también del positivo, en que no requiere de manera imprescindible la intervención del contrato o de la positivación). Pero — dice Gómez Robledo- es problemático que Tomás haya puesto a los animales como sujetos de derecho (natural). Explica que esto lo hizo como una concesión a Ulpiano. Me parece que a esta exégesis de Gómez Robledo se le escapa que la atribución de derecho a los animales es meramente analógica e impropia, que sólo es propio y perfecto en los hombres. Sin embargo, tal vez lo más discutible en la exégesis de Gómez Robledo es que no deja ver con claridad si el derecho de gentes es algo completamente distinto del derecho natural o si es sólo una subdivisión de éste, en el sentido de ser no la parte absoluta del derecho natural, sino una parte relativa o más contingente. Falta distinguir en el derecho natural un grupo de conclusiones derivadas de manera próxima y otras de manera remota, siendo, lógicamente, las primeras más naturales que las segundas. Hay, pues, un derecho natural primario, que contiene los primeros principios, y un derecho natural secundario, que contiene las conclusiones directas e inmediatas obtenidas de esos principios por deducción necesaria. Este derecho secundario es precisamente el derecho de gentes. Pero no es una mera parte del derecho natural, se distingue tanto del derecho natural como del derecho positivo, tiene su propia especificidad y es intermedio entre ellos, por lo cual, según diferentes puntos de vista, se puede decir natural o positivo (si se compara con el natural primario, es positivo, y si se compara con el positivo, es natural). Lo diferencial en él es que no se aplica a todos los animales, sino sólo a los racionales, a los hombres, siendo por ello un derecho natural humano en sentido estricto. Pero no necesariamente 
tiene que estar positivado. Así se distingue el derecho de gentes del derecho natural y del derecho positivo. ${ }^{6}$

Gómez Robledo analiza un problema difícil de la doctrina tomista, en la que ésta se aparta de la aristotélica, a saber, el de la mutabilidad del derecho natural. Lo resuelve bien diciendo que, en cuanto a la parte absoluta o que se refiere a la naturaleza humana como tal o en universal, es invariable, $y$, en cuanto a la parte relativa o que se refiere a la naturaleza concreta de este o aquel individuo, es mudable, ya que también en este sentido la naturaleza humana es mudable, como ya lo había dicho Aristóteles.

Problema fuerte es igualmente el de algunas instituciones del derecho de gentes y que resulta muy difícil creer que se deriven de la ley natural, como la esclavitud: eso de que es mejor para algunos hombres ser regidos por otros más sabios, pues "para esto no es necesario un título jurídico de dominio sobre su persona".? Pero Gómez Robledo dice que son errores de grandes inteligencias que, sin embargo, dejan incólume la doctrina general del derecho natural y de gentes.

Otra cosa que Gómez Robledo ve en la concepción del derecho de gentes de Santo Tomás es que con ella

ha sido uno de los precursores del derecho internacional, aunque ciertamente no uno de sus fundadores. De esto, empero, no puede hacérsele ningún reproche, como quiera que no pudo tener, en el mundo en que vivía, la experiencia vital de la situación histórica que hizo posible el derecho internacional, o sea la aparición de otro mundo distinto de la república cristiana medieval (en la cual había a lo más un derecho de tipo confederal), y que no le fuera en principio hostil, como lo era el mundo del Islam, en guerra permanente con la Europa cristiana. Ahora bien, este en todos sentidos nuevo mundo iba a serlo el continente americano, y hasta entonces no sería posible plantear la posibilidad de un derecho internacional. ${ }^{8}$

Pero cupo la suerte de ser el fundador a un discípulo suyo y hermano de hábito del siglo XVI, de ese momento de descubrimientos y de conquistas, a saber, Francisco de Vitoria.

Gómez Robledo se fija acertadamente en que Santo Tomás corrige en una palabra la definición que Ulpiano daba de la justicia, pero que fue una corrección fundamental. Ulpiano decía que ella era la voluntad constante y perpetua de dar a cada uno su derecho y el Aquinate le añade que es un hábito por el cual se tiene esa voluntad. En efecto, cabe señalar que la ambigüedad estaba en la palabra "voluntad" sola. Santo Tomás había comentado que no se tomaba aquí "voluntad" en su sentido de facultad, pues

${ }^{6}$ Cfr. S. Ramírez, El derecho de gentes, Studium, Madrid, 1955, pp. 106 ss.

7 Ibid., p. 112.

8 lbid. 
eso parecería estar aludiendo al acto aislado y esporádico de la misma (y, por lo tanto, supeditada al capricho de la persona), sino que se trata de un hábito, lo que permite que sea una virtud, una actitud más que un acto. $\mathrm{Al}$ hablar de virtud, se está colocando al derecho en el ámbito de la moral. Para Gómez Robledo esta postura tomista es correcta, a pesar de que después de Kant se luchó tanto por separar esas dos áreas y preservar la autonomía de la móral. Esa separación - como la otra entre moral y política - ha llevado a muchos problemas y a tener que positivar los derechos humanos, olvidando que ya por anticipado son derechos naturales.

Un apartado muy importante es el que dedica Gómez Robledo a reflexionar sobre la acusación de Kelsen al iusnaturalismo de pasar falazmente del ser al deber ser. Dice que esta objeción no se aplica al Aquinate, ya que "en el iusnaturalismo de Santo Tomás el deber ser nos es dado directamente por la voluntad divina, y la naturaleza es apenas el registro de su promulgación. Si en el hombre debemos respetar su naturaleza racional y social (y aquí está, en fin de cuentas, toda la justicia y el derecho) es por la norma divina y no porque deduzcamos el deber de la sola consideración de la naturaleza. No hay, pues, ningún tránsito indebido del ser al deber ser, alguna confusión entre hecho y norma, entre valor y realidad. Es del Bien Sumo, del Supremo Valor, del que procede directamente la norma. En Dios mismo, claro está, son completamente indiscernibles, por ser todo uno y lo mismo, Ser y Valor (Summum Ens, Summum Bonum)."9 A mí me parece, a diferencia de Gómez Robledo, que hay otra forma de bloquear la objeción de falacia de pasar ilegítimamente del ser al deber ser, sin acudir al origen divino de la naturaleza y, por lo mismo, de la ley natural. Sin tomar en cuenta a Dios como legislador, se pueden revisar los aspectos lógicos de ese paso del ser al deber ser y mostrar que no hay falacia ninguna. En efecto, si disminuimos la separación fatal entre hecho y valor -como es algo que se está dando mucho en la filosofía más reciente, por ejemplo, en la analítica-, podemos ver que en los hechos mismos hay una carga de valor, en la naturaleza hay cierta moralidad, el ser apunta a un deber ser y con ello no se hace ningún paralogismo, sino que sólo se explicita lo que estaba precontenido e implícito en lo natural. De este modo el deber ser se explicita a partir del ser, en el cual ya estaba presente y así no se saca en la conclusión más de lo que estaba en las premisas, es decir, no se comete ninguna falacia.

Gómez Robledo compara el iusnaturalismo aristotélico-tomista con el moderno y hace algunas críticas muy certeras a este último. La primera es que el iusnaturalismo moderno mezcló la historia con la filosofía del derecho al hablar de un ficticio "estado de naturaleza" del hombre, anterior a su socialización, como si se hubiera dado realmente en una edad remotísima.

9 Ibid., p. 118. 
Así habrian coincidido el derecho natural y el derecho positivo porque se habrían dado los dos por igual en cierto tiempo. Pero al mezclar el derecho natural con el positivo, su valor moral quedaba reducido a valor histórico. Aquí sí se daría la falacia de pasar del ser al deber ser, si se quisiera pasar de ese estado histórico de naturaleza a su obligatoriedad universal para los seres humanos.

Otra objeción contra el iusnaturalismo moderno es su deductivismo. Se quiso inferir tanto a partir de los principios del derecho natural que se ponía dentro de tal derecho una lista larguísima de preceptos derivados. No en balde el título de la obra de Morelly fue Code de la nature, como si se pudiera derivar todo un código de la razón larguísimo y a la postre muy discutible. En cambio, para Santo Tomás, sólo unos pocos principios y unos pocos preceptos derivados de ellos tenían la evidencia necesaria. Según Gómez Robledo, esos modernos abultaban tanto el derecho natural que hacían redundante e inútil el positivo. Podían legitimar cualquier cosa, tanto el absolutismo o totalitarismo como el liberalismo o individualismo. Y de esta forma el iusnaturalismo fue cayendo en descrédito, pues se volvía vago en su contenido estructural y en sus derivaciones.

En cambio, según Gómez Robledo, el iusnaturalismo aristotélico-tomista no comparte los vicios del moderno. "Puede haber incidido en ellos ocasionalmente, es verdad, en tal o cual de sus representantes; pero en la doctrina misma ha habido siempre los suficientes recursos para poder corregir, sin salir de ella, estas desviaciones." 10 En él no se alude a un estado de naturaleza ni se cae en la positivación del derecho natural. La idea del paraíso no pasó en el Aquinate de la sociedad conyugal de Adán y Eva, por lo que no puede aplicarse a toda la sociedad civil; no se trata de un estado civil paradisiaco. En cuanto al deductivismo, Santo Tomás no incurre en él. Más aún, distingue entre conclusión y determinación de los principios del derecho natural. ${ }^{11}$ De este modo, según Gómez Robledo, más que de derivaciones lógicas propiamente, debería hablarse de determinaciones a las que obligan las circunstancias particulares. Esas determinaciones no se dan por inferencia lógica, sino por aplicación prudencial. Están más del lado de la prudencia que de la lógica. Sólo debemos decir que aquí le faltó un poco de exactitud a la exégesis de Gómez Robledo. En efecto, Santo Tomás admite los dos modos de derivación a partir del derecho natural, a saber, la deductiva y la determinativa:

Esta derivación puede verificarse de dos maneras. Una, en forma de conclusiones universales próximas o remotas, fáciles o difíciles, de los principios universalísimos de la sindéresis, que constituyen y contienen esencialmente la ley y el derecho natural puramente tales; por ejemplo, de este principio universalísimo,

10 Ibid., p. 121.

11 Cfr. Santo Tomás, Summa theologix, I-II, q. 95, a. 2. 
que no debe hacerse mal a nadie, se deriva a modo de conclusión este otro: que no debe matarse a nadie. Otra, en forma de simple determinación concreta de los principios universalísimos o de las conclusiones universales; por ejemplo, de este principio, que todo malhechor debe castigarse, se deriva como simple determinación la cantidad y el modo de la pena que debe imponerse al homicida o al ladrón, es decir, tal indemnización, encarcelamiento, pena capital u otras (I-II, q. 95, a. 2). ${ }^{12}$

Admitir, además de la determinación de los principios, algún tipo de deducción lógica restringida no es caer en el deductivismo en el que incurrieron los modernos.

Hay que precisar también la vigencia y el alcance de los preceptos de la ley natural, pues no es la misma en los primeros principios, que son universalmente válidos, y en los preceptos derivados, conclusiones de esos principios, que tienen que mudarse de acuerdo con las situaciones históricas. Así es el derecho de gentes, en el que se contienen ciertas conclusiones del derecho natural. Ha habido polémica entre los intérpretes del Aquinate en este punto de la inmutabilidad de los preceptos de la ley natural: cuáles sí lo son y cuáles no. Gómez Robledo interpreta en este sentido a Santo Tomás:

Las mismas conclusiones del derecho natural, si no hemos entendido mal a Santo Tomás, no tienen la vigencia incondicionada de los primeros principios, y su aplicación, por lo mismo, no es ya tan perentoria. Es en el derecho de gentes precisamente donde se contienen las conclusiones de la ley natural; pero, como ya vimos, se tiene siempre en cuenta una situación histórica, al mudar la cual puede muy bien nacer otra norma o institución. Si la satisfacción de las necesidades económicas y la paz social, por ejemplo, pueden asegurarse de otro modo que por la propiedad privada, no hay al parecer un obstáculo insalvable para su abolición, ya que son aquellos los dos únicos motivos que ha habido para mantenerla (ad opportunitatem colendi et ad pacificum usum agri); y no está demostrado por lo menos que Santo Tomás excluya otra solución. En la sociedad de artesanos independientes en que él vivió, el derecho de propiedad sobre los medios de producción era la protección debida a la realización solidaria de una obra socialmente útil; pero en un mundo de técnicas industriales en gran escala, el mismo derecho implica y consolida jurídicamente la explotación de la mayoría por la minoría. Lo mismo en lo tocante a la servidumbre o vasallaje, en cuanto para los sometidos deje de ser "útil" su dirección por individuos o pueblos más esclarecidos (a sapientiori), y no porque hayan superado su condición de atraso, sino por encontrar más útil la posesión inmediata del bien moral de la independencia. ${ }^{13}$

13 A. Gómez Robledo, op. cit., p. 122. 
Así, en la exégesis de Antonio Gómez Robledo, Santo Tomás quiere sostener que los principios de la ley natural son inmutables, pero las conclusiones no lo son, sino que deben adaptarse a la circunstancia histórica. Esta reflexión es muy importante, porque en la ley natural ha de haber principios que fundamenten todo, y en ese sentido sean inamovibles - como hacer el bien y evitar el mal, no matar cuando no es en legítima defensa, no cometer perversiones, etc.-, y otros tienen que variar en algo de acuerdo con el momento en que se dan, y al que determinan lo que estaba en los principios, como la propiedad privada, la servidumbre, etcétera.

Una cosa más que resulta importante es lo que asegura Gómez Robledo: que la doctrina iusnaturalista de Tomás no estaba comprometida con un régimen político determinado, a diferencia del iusnaturalismo moderno, cuyos propugnadores ilustrados dependían de alguno al que servían. No sólo es falso decir que el iusnaturalismo tomista estaba pensado en función de la monarquía que se daba en Europa en ese momento, sino que, antes bien, "se han aducido numerosos textos del De regimine principum como demostración del relativismo político y de la independencia en que estuvo, frente al poder temporal, quien por el estado que libremente abrazó, no tuvo que pedir nada del poderoso". ${ }^{14}$ Finalmente, esta doctrina iusnaturalista no fue sólo la de Tomás, sino que llegó a ser la predominante en la cristiandad durante muchos siglos, a través de sus discípulos. Tanto los escolásticos medievales como los posmedievales (Vitoria, Soto, Las Casas y otros) la ampliaron y la desarrollaron, pero en el espíritu tomista de búsqueda de la justicia. "Podrán faltar - concluye Gómez Robledo-, en aquellas épocas, las declaraciones de derechos hümanos; podrá discutirse interminablemente si la ley natural radica en la razón o en la voluntad divina, o si en ambas y de qué modo; podrá inclusive declararse al gobernante exento de toda sujeción a la ley positiva, pero con todo ello, la supremacía de la ley natural, y su absoluta plenitud jurídica, es algo que para la Edad Media está fuera de toda discusión." ${ }^{15}$ Eso impidió que los tiranos estuvieran por encima de la ley, pues al menos la ley natural se oponía a las acciones injustas que hacían $\mathrm{e}$ incluso a las leyes inicuas que promulgaban. $\mathrm{Y}$ eso nos hace pensar que Gómez Robledo, a diferencia de algunos tomistas - como Villey, Lachance y otros-, aceptaba dentro del tomismo la validez de los derechos humanos como algo equivalente a los derechos naturales del hombre y poco a poco llevados a su positivación. 


\section{Conclusión}

Según hemos visto, Antonio Gómez Robledo hace una competente exposición de la teoría de la justicia en Santo Tomás. No extraña el que dé prioridad a la noción de derecho natural, ya que la justicia es el objeto del derecho, según se hizo ver en la escolástica del siglo de oro, con tratados intitulados De iustitia et iure, la justicia y el derecho estaban intimamente asociados. Así entendemos también por qué dijo: "A partir de mi último libro, Meditación sobre la justicia, empecé a trabajar sobre el derecho natural, que remite a un segundo orden más allá del derecho positivo, ya sea que se le conciba en la antigua concepción teológica o en la nueva concepción racionalista; un segundo orden frente a la tiranía y la arbitrariedad del déspota. El gran renacimiento del derecho natural vino después de la Segunda Guerra Mundial, como respuesta a las atrocidades de los nazis, empezando por el genocidio en los campos de exterminio. Es un tema apasionante en la historia del derecho."16

La teoría del derecho natural ha servido, pues, para denunciar tiranías e injusticias más allá de lo escrito en el derecho positivo. Por eso es complemento y plenitud de la noción de justicia, base suya y tope, fundamento y culmen. No hay justicia completa si no se da al hombre lo que se le debe por su esencia, por su naturaleza, y ello obliga a conocer al hombre mismo, para poder ayudarlo a realizarla, y eso va más allá de lo que esté positivado, $\mathrm{e}$ incluso es independiente, anterior o superior, a lo que esté positivado, esto es, sancionado en el derecho positivo. Es la única medid a que puede hacer ver que el derecho positivo está mal y que hay que corre,,irlo. Por eso, también, Antonio Gómez Robledo no pudo dejar de tocar el de: echo natural, en su afán de realizar en todas sus formas lo justo, constituyéndose en lo que Cicerón llamaba, en una de sus cartas, un vir plane bonus.

16 Es una de las respuestas en la "Entrevista con el doctor Antonio Gómez Robledo", en Antonio Gomez Robledo. Imagen y obra escogida, ed. cit., p. 10. 